\title{
Blood Inflammatory Marker
}

National Cancer Institute

\section{Source}

National Cancer Institute. Blood Inflammatory Marker. NCI Thesaurus. Code C143955.

A substance detectable in the blood that can be used to assess levels of inflammation in the body. 